\title{
Development of a descriptive monocultural model for creating an innovative organization
}

\author{
Yuri Polyakov ${ }^{3}$, Mikhail Savelyev ${ }^{1}$, Denis Perevedentsev ${ }^{1}$, Olga Titova $^{2}$, and Marina \\ Galiakhmetova $^{2}$ \\ ${ }^{1}$ Mitra Association, Pushkinskaya Str., 241, 60, 426008 Izhevsk, Russia \\ ${ }^{2}$ M.T. Kalashnikov IzhSTU, Studencheskaya Str., 7, 426069 Izhevsk, Russia \\ ${ }^{3}$ Udmurt State University, Universitetskaya Str., 1, 426034 Izhevsk, Russia
}

\begin{abstract}
A methodology for designing an innovative organization has been developed within the framework of a descriptive approach to draft design in monocultural environments of the organization as a whole and of individual managers. The definition of single design elements is proposed as a design tool. The design basis is the conceptual sketch of the organization's activities, which includes the elements of resources, added value, product, its value and demand for it, defined as a single production operation. A classification of types of homogeneous products according to their purpose and resources used has been given. The classification of types of homogeneous products for industrial purposes includes tools, fixtures, machine and equipment, areas, structures and infrastructure. The problems of choosing a product and using the resource have been solved. This methodology is recommended for use by managers and professionals involved in the design of organizations.
\end{abstract}

\section{Introduction}

An innovative organization is a pillar of sustainable economic growth, increasing the competitiveness of the national economy. Namely, through the prism of the competitiveness of individual national companies, M. Porter explained that the general level and dynamics of development of the country's economy depends on the achievements of specific firms representing the country in the foreign market [1-12].

The model is a kind of "cognitive map of the area" based on the cognitive theory of learning by Edward Tolman, developed in 1932 [13]. It prescribes what needs to be done to increase the likelihood of a favorable outcome. The development of a descriptive monocultural model of creating an innovative organization (hereinafter referred to as the model) allows you to manifest, visualize the process of designing and constructing an organization.

Designing and constructing a monocultural innovative organization (hereinafter referred to as the organization) is a complex multistage process. In our opinion, it is possible to construct a basic algorithm by simplifying the concept of an innovative organization by introducing several concepts:

A single production operation is a complete technological process or a part of a technological process, in which, over a standardized period of time, one complex of production purposes (tool-device-machine) is used to manufacture a single product, with the participation of a person with a set of technical competencies. 
A single product is a finished product manufactured in a single operation, intended for final or intermediate consumption, as well as an element used in a more complex design.

Homogeneous product - products that are identical in design and manufacturing technology, have the same or similar functional purpose and differ in the quantitative level of the main consumer property.

A single homogeneous resource is a type of resource used in a single operation for the manufacture of a homogeneous single product,

A single product for industrial purposes is a type of industrial complex for equipping a single operation.

In our opinion, these are basic elements, constructive bricks, from which, like a mosaic, the activities of an organization are formed.

\section{Materials and Methods}

The main proposed approach to the design and construction of a single product-operation is a sketch design of the activities of the organization as a whole and the activities of individual managers. Sketch design is an analogue of the conceptual design of a product, the first conceptual stage of organizing the organization's activities.

Conceptually, with the help of sketch design, the design of the following elements of the organization's activities can be shown:

- single operation (production activities of the organization),

- single homogeneous product, the result of a single operation (production activity);

- single homogeneous resource required for a single operation (innovation and procurement activity),

- single product for industrial purposes to equip a single operation (innovation and investment activity);

- The functionality of the organization consists in the following actions:

- formation of the value of a single product,

- formation of a value chain,

- formation of demand for a resource and a product of industrial purpose,

- formulation of equilibrium conditions under which the entire product produced by the organization is consumed.

\section{Results and Discussion}

An initial conceptual sketch of the organization's activities is shown in Figure 1. 


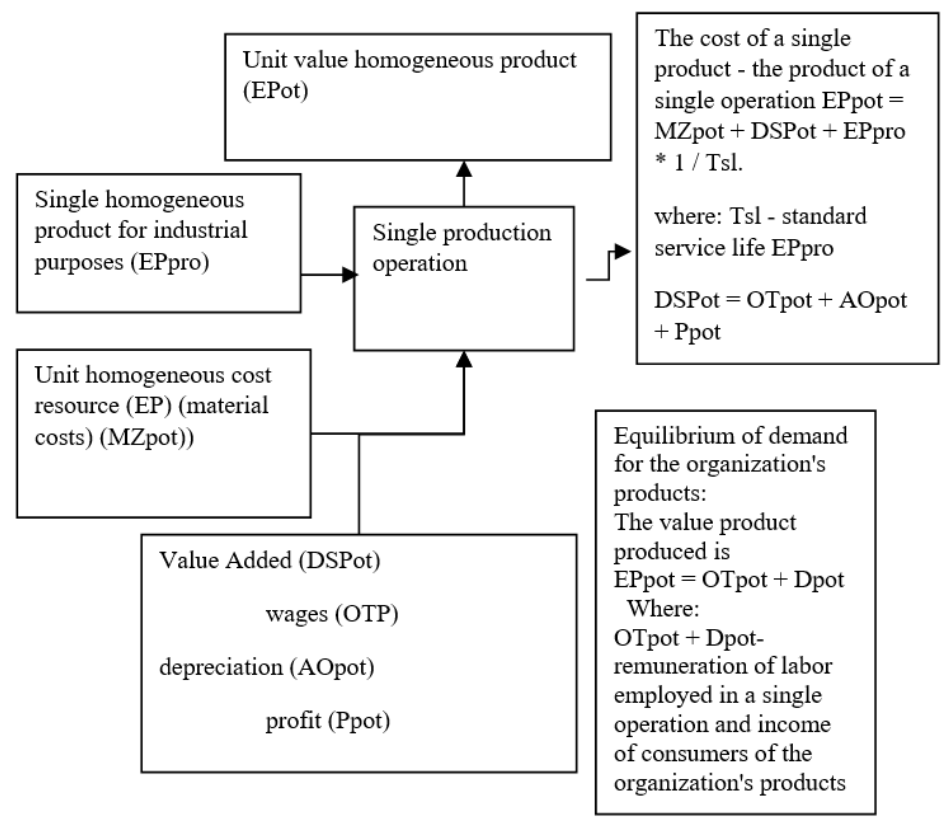

Fig. 1. Conceptual sketch of the organization's activities

It turns out that the simplest, elementary organization has been designed, producing one homogeneous product, consuming one homogeneous resource and a homogeneous product for industrial purposes. The variant of arrangement of the organization's activities from the minimum number of elements has been chosen.

Further design of the organization is carried out in the following sequence in the direction of concretizing the selection of the type of the following elements of activity:

homogeneous product for the organization of production activities;

homogeneous resource for a single product-operation;

production product to equip a single operation.

single operation (parameters of the production capability of the organization).

The choice of the type of a homogeneous product of the organization is as follows: will the organization produce a certain type of agricultural products or a product for industrial purposes or a final product for consumption by the population. The basis for choosing the type of a homogeneous product for organizing production activities is the classification of types of products. The classification of types of homogeneous products is shown in Figure 2. The choice of the organization's product is carried out either on the basis of ready-made or purchased product innovations (industrial design, recipe, utility model, etc.). For each of these choices, the rationing of the value structure of a single homogeneous product is carried out either by the experimental statistical method or by the normative method based on the norms of the value structure or by the analog method based on the structure of the value of analog products. The price of the product is calculated by the method of calculating the cost elements and standard profit. The equilibrium condition is specified, the price of the organization's product is equal to the individual income of an employee in the organization or the individual income of the consumer of the organization's product. 
- Types of homogeneous products produced for a single operation

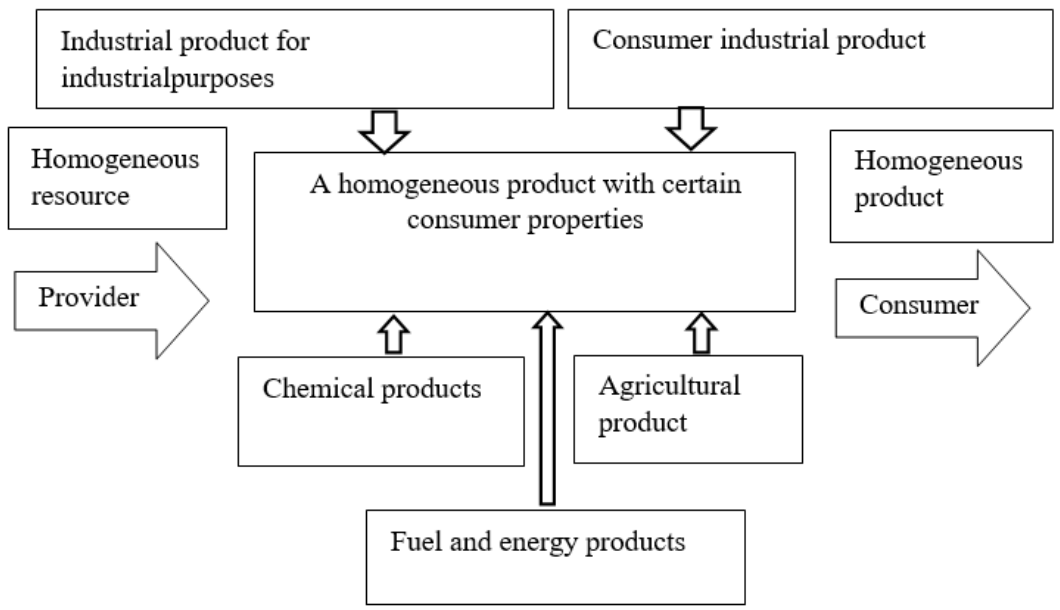

Fig. 2. Classification of types of homogeneous products

The selection of a homogeneous resource is as follows: whether the organization will use a biological resource or agricultural product or an industrial product to produce its product. The basis for choosing the type of a homogeneous resource for the production of an organization's product is the classification of types of the resources. The classification of types of homogeneous resources is shown in Figure 3. The selection and justification of the types of resources for a single product-operation is carried out either on the basis of innovative resources produced by a specialized manufacturer or on the basis of recoverable natural resources with unique properties or extracted biological resources with unique properties. For each of these choices, the rationing of the consumption of resources for the production of the organization's product is carried out either by the experimental statistical method or by the standard method or by the analog method of resource consumption in the manufacture of analog products. An acceptable price of resources is calculated, which ensures the maximum marginal profit, the consumption of a natural resource is rationed and the specific consumption of this resource is calculated per unit of the finished product.

- Resource equipping of a single product-operation with types of a homogeneous resource

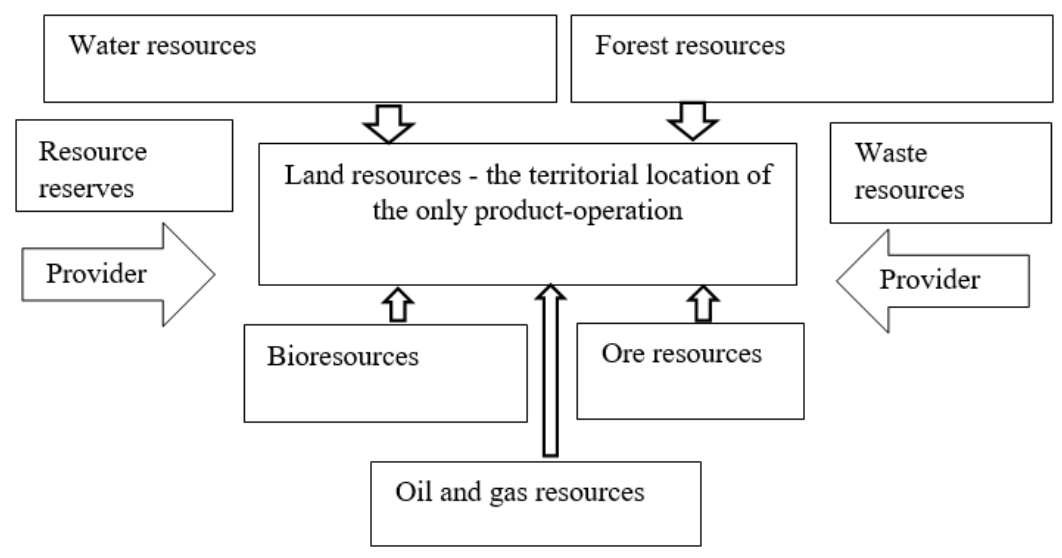

Fig. 3. The types of resources required for a single product-operation 
The selection of the type of industrial product for equipping a single operation is as follows: equipping is carried out either on the basis of innovative products produced by specialized manufacturers or on the basis of our own innovative proposals for specialized manufacturers or on the basis of acquired innovative proposals for specialized manufacturers of industrial products.

- Technological equipment of a single product-operation with types of a

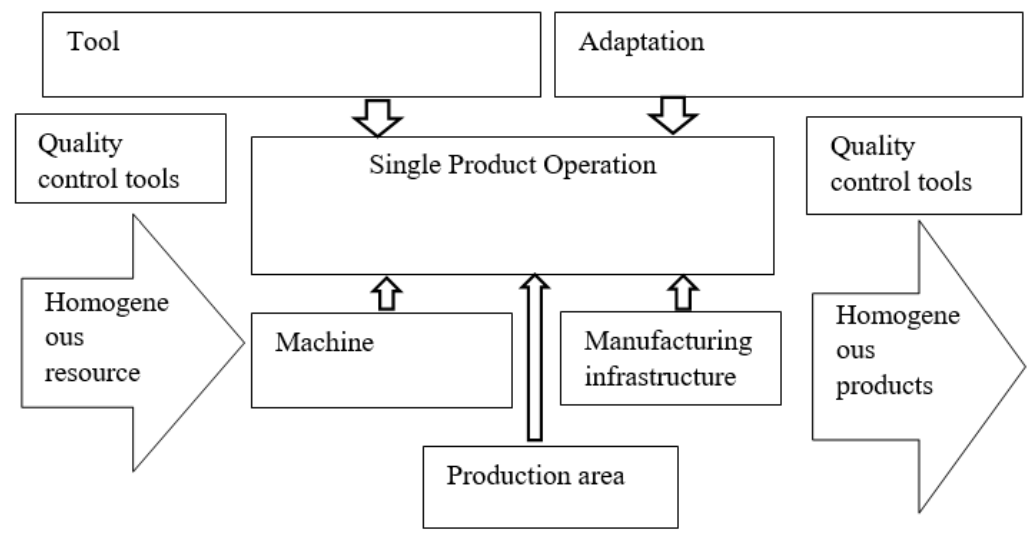

Fig. 4. Classification of types of homogeneous industrial products

For each of these choices, the number of units of a production product for the production of an organization's products is rationed either by an experimental statistical method or a regulatory method or by an analog method of using production products in the manufacture of analog products. The standard service life of a production product is determined, depreciation charges are calculated either on a straight-line basis or by an accelerated depreciation method. An acceptable price for a production product is calculated, which ensures the minimum payback period or the maximum interest income on the funds invested in the production product.

\section{Conclusions}

The resulting methodological tools are applicable to the creation of an innovative organization in a monocultural environment with regard to product design and resource use. This approach allows to ensure the complexity and integrity of the creation of innovative organizations.

\section{Acknowledgements}

The reported study was funded by RFBR, project number 20-010-00869

\section{References}

1. M. E. Porter, Competitive Advantage: Creating and Sustaining Superior Performance, $592(1985)$

2. M. E. Porter, Competitive Advantage of Nations, 896 (1998)

3. M. E. Porter, On Competition (1998) 
4. M. E. Porter, Takeuchi, H., Sakakibara M., The Japanese economic model, Can Japan compete?, 262 (2005)

5. M. E. Porter, Elizabeth Olmsted Teisberg, E. O. Redefining, Health Care: Creating Value-Based Competition on Results, 506 (2006)

6. M. E. Porter, Harvard Business Review, May/June, 43 (1987)

7. M. E. Porter, Strategic Management Journal, 12, 95 (1991)

8. M. E. Porter, Harvard Business Review, Nov/Dec (1996)

9. A. M. McGahan, M. E. Porter, Strategic Management Journal, 18, 15 (1997)

10. M. E. Porter, Harvard Business Review, 62 (2001)

11. M. E. Porter, M. R. Kramer, Harvard Business Review, 78 (2006)

12. Joan Magretta. M. E. Porter, Mann, Ivanov and Ferber, 272 (2013)

13. E. Ch. Tolman, General psychology, 2, 479 (2013) 